\title{
Role of development communication in fostering social change: evidence from Lesotho
}

\author{
Sergio Carciotto and Mulugeta F. Dinbabo
}

\begin{abstract}
A number of programmes have been implemented in the field of development communication with the specific aim of promoting social change among communities. Series of studies have also illustrated the positive effects of Entertainment-Education (EE) interventions on individuals' behavioural change. In line with the theory and conceptual framework of the Integrated Model of Communication for Social Change (IMCSC), this research empirically explored how development communication programmes can foster collective action amongst community members in Lesotho using media to promote social transformation and individual change. Both quantitative and qualitative research methods of enquiry were employed throughout the research. The results of the study reveal that firstly, development communication initiatives are able to foster collective forms of action by increasing the level of self-efficacy amongst the audience. Secondly, participatory development communication with an educational aim allows people to identify problems and to strategise and mobilise resources for collective action.
\end{abstract}

\section{Introduction}

Development communication is a "two-way communication systems that enable dialogue and allow communities to speak out, express their aspirations and concerns and participate in the decisions that relate to their development" (McCall 2011: 7). It has played a fundamental role within the discourse around different development practices, and a variety of programmes based on the use of media have been implemented worldwide in the field of agriculture, literacy and HIV/AIDS prevention (Shefner-Rogers et al. 1998; Brown and Singhal 1999; Papa et al. 2000; Tufte 2001, 2002).

A series of studies illustrate the positive effects of development communication interventions such as entertainment-education (EE) programmes broadcasted on TV and radio, with regard to individual behaviour change (Singhal et al. 1993; Obregon and Waisbord 2012; Rasak and Adesina 2011). Scholars (Singhal et al. 1993; Shefner-Rogers et al. 1998; Rasak and Adesina 2011; Obregon and Waisbord 2012) have also examined the role of development communication in fostering social change.

A critical review of the literature around the issue of development communication shows that strategies of communication based exclusively on individual behaviour change, 
such as behaviour change communication (BCC) are not change if they are not combined with the analysis of social structure, local norms and interpersonal networks. Against this background this research is based on a case study of Sesotho Media and Development (SMD), a non-governmental organisation that use media to promote social change. SMD conducts facilitated post-screening discussions around Lesotho and operates with the following objectives: to increase awareness and knowledge about HIV/AIDS and issues such as treatment, gender, culture, discrimination and stigmatisation amongst the target groups; to emphasise the importance of reaching the youth, support group members and prison inmates; to create an enabling environment wherein the public can speak openly and in a non-discriminatory way about the HIV virus and/or their own status and to encourage individuals and communities to take action based on informed decision with regard to HIV/AIDS prevention, positive living, and support for others.

The purpose of this research was to determine how the Integrated Model of Communication for Social Change is applicable to the communication for development programmes implemented by SMD. In general, it seeks to answer the following research question: How can development communication programmes implemented in Lesotho by SMD initiate and foster collective action among community members in Maseru and the Berea District, including Maseru Central, Leribe and Mafeteng prisons? In order to measure the outcomes of development communication interventions run by SMD and to describe how "community dialogue and collective action can work together to produce social change" Figueroa et al. (2002) designed a model named the Integrated Model of Communication for Social Change (IMCSC) which was applied to the case study.

The Integrated Model of communication for Social Change (IMCSC) is the result of a combined approach to development communication, which includes "individual behavioural outcomes and social-change outcomes" (Figueroa et al. 2002: 3). The main assumption behind it is that participation and community engagement are the core elements of every communication process and can lead to collective action. This model is inspired by the concept of dialogical action developed by the Brazilian educator Paulo Freire (1972) and by a people-centred body of theories that define communication as a twoway participatory process, based on dialogue. Through dialogue, media and communication can empower individuals and communities and initiate a critical process of analysis and understanding that can lead to individual and structural change.

The model is designed to overcome the limitations of one-way individual behaviour change strategies and its main assumption is that social change requires more than a shift in individuals' behaviours but rather a collective effort to produce results that are more effective. The model draws from a convergence/network model of communication (Kincaid 2000, 2002; Rogers 1976; Rogers and Kincaid 1981), which describes communication as a process of dialogue and interaction between individuals that leads to collective action. It places a strong emphasis on the role of social networks, norms and interpersonal communication to determine forms of collective action and structural change. The IMCSC is aimed at explaining how community dialogue and collective action can produce social change. According to the IMCSC the process that leads to collective action through community dialogue is initiated by a catalyst (that is, mass media, change agent, policies or internal stimulus) which triggers discussion among audiences. Once the 
discussion is initiated, participants undergo through a series of different stages: firstly an assessment phase which includes: identifying the problem and the relevant key stakeholders to deal with it together with a common vision for the future; secondly a phase of planning that includes setting objectives, options of action and finally an action plan. In essence, the information produced by media might acts as a catalyst of the process. The identified problem is consequently discussed among community members who, after a process of attaining mutual understanding, decide collectively on how to tackle a certain social issue. This process is based mainly on community dialogue and collective action and is intended to promote participation and foster people's empowerment.

Entertainment-education programmes (Brown and Singhal 1996; Singhal et al. 1998; Rogers and Singhal 2002) are an example of how different media (that is, TV, radio, cinema and theatre) can make people interact and debate on a particular social issue. Once the dialogue is initiated, audiences start receiving critical information and become more aware of the problems affecting their communities. This process of critical social learning is comprised of a series of steps and alternates moments of agreement with moments of conflict and disagreement until a final consensus is reached by community members. Once the problem is identified and possible solutions become clearer, an action plan is drafted and roles and responsibilities are assigned to different individuals. This is a fundamental step because it leads to mobilisation and ultimately to forms of collective action. The concept of collective self-efficacy becomes central in the discourse around social change, together with dialogue and participation.

\section{Methodological approach}

This research employed a mix methodology of secondary data analysis, quantitative and qualitative data collection to understand issues involving collective self-efficacy. A purposefully selected 16 people were interviewed. In addition, a self-administered questionnaire was designed and was distributed to a sample of 52 respondents, to measure, exclusively, the level of collective self-efficacy, as a main outcome of the process of dialogue and social learning between audience and a facilitator, as per described by the IMCSC. The choice of a selective quantitative analysis of collective selfefficacy, as an independent variable, was made with the intent to understand how the development communication programmes, implemented in Lesotho by SMD, initiate and foster collective action. The research undertook focus group interviews with two groups of people in the case study area, that is, the SMD management team and members of different support groups in the Berea District. Participants' observations have been made and meetings at different levels were also conducted. These meetings enabled the researchers to understand the different views, experiences and perspectives of the participants towards how development communication and dialogue could foster collective action among communities.

\section{Results and analysis}

The analysis of quantitative data and the interpretation of item analysis firstly revealed that respondents presented a high level of collective self-efficacy, described as the group's shared belief in its ability to perform a given task (Bandura 1986). A high level of collective self-efficacy was measured on all its three dimensions: 
1. the perceived efficacy to take action as a group;

2. the perceived capability of other community members; c) the perceived efficacy to solve problems as a group. Figueroa et al. (2002) provided a series of quantitative tools to measure the level of collective self-efficacy, of which some were applied to this study.

Respondents had an option, on the Sesotho version of the questionnaire, to choose from three different answers on a Likert-type scale. Because answers on the questionnaire were not presented on an ordinal scale, they subsequently had to be re-coded by using an ordinal scale from " 1 " to " 3 " in order to be easily analysed. Positive answers where therefore coded with a value of " 3 " on the scale, negative with a value of " 1 ", while those that did not fall within these categories were coded as " 2 ". According to this coding system," 1 " represents a low level of self-efficacy, "2" a neutral level of self-efficacy and " 3 " a high level of self-efficacy. In general, in this research, to facilitate data analysis, each response category on the Likert-type scale was successively assigned an integer value.

The first two sets of questions in the questionnaire (see Tables 1 and 2,) aimed at measuring, respectively, the level of self-efficacy perceived amongst support group members and the level of self-efficacy or confidence in working constructively with other community members. The Cronbach's alpha coefficient ( $\square$ ) for the first two sets of questions (Q1 to Q11) was .8 > $\square \square .7$, indicating an "acceptable" and reliable coefficient of internal consistency. This means that respondents placed enough confidence in the skills and knowledge of their support group and that their community looks cohesive and able to mobilise resources and implement the action planned. 
Table 1: Cronbach's Alpha Value ( $\alpha$ ) for the first set of three questions

\begin{tabular}{llrr}
\hline & & $N$ & $\%$ \\
\hline Cases & Valid & 51 & 98.1 \\
& Excluded $^{\mathrm{a}}$ & 1 & 1.9 \\
\hline \multicolumn{2}{c}{ Total } & 52 & 100.0 \\
\hline a. Listwise deletion based on all variables in the procedure \\
Reliability Statistics \\
\hline Cronbach's Alpha & N of items \\
\hline .719 & & 3 \\
\hline
\end{tabular}

Table 2: Cronbach's Alpha Value ( $\alpha)$ for the second set of eight questions

Case Processing Summary

\begin{tabular}{lrr}
\hline & $N$ & $\%$ \\
\hline Cases Valid & 51 & 98.1 \\
Excluded & 1 & 1.9 \\
\hline \multicolumn{1}{c}{ Total } & 52 & 100.0 \\
\hline Reliability Statistics & & \\
\hline Cronbach's Alpha & & N of items \\
\hline .778 & & 8 \\
\hline
\end{tabular}

The last set of questions (see Table 3) was intended to establish a causal relationship between the perceived level of collective self-efficacy and the effect of SMD methodology and training programmes. In this case, the test of reliability produced a Cronbach's alpha coefficient of .7 > $\square \square \square \square .6$, which is generally considered "questionable" and not fully reliable. Therefore, a further elaboration on the available data was conducted primarily to better understand the relationship between documentary screening and level of selfefficacy.

A $t$-test run on the last set of three questions (Q12, Q13, and Q15) scored a ( $\square$ ), close to a positive value of " 3 ", indicating a high value of self-efficacy (see Table 4). This means that respondents generally agreed that screening programmes and post-screening discussions helped support group members and health care villagers to discuss issues related to HIV/Aids, to initiate dialogue and to take action as a group. This fact reinforces the theory that development communication interventions developed by SMD can increase the overall level of self-efficacy and ultimately lead to collective forms of action. 
Table 3: Cronbach's Alpha Value $(\alpha)$ for the third set of three questions

Case Processing Summary

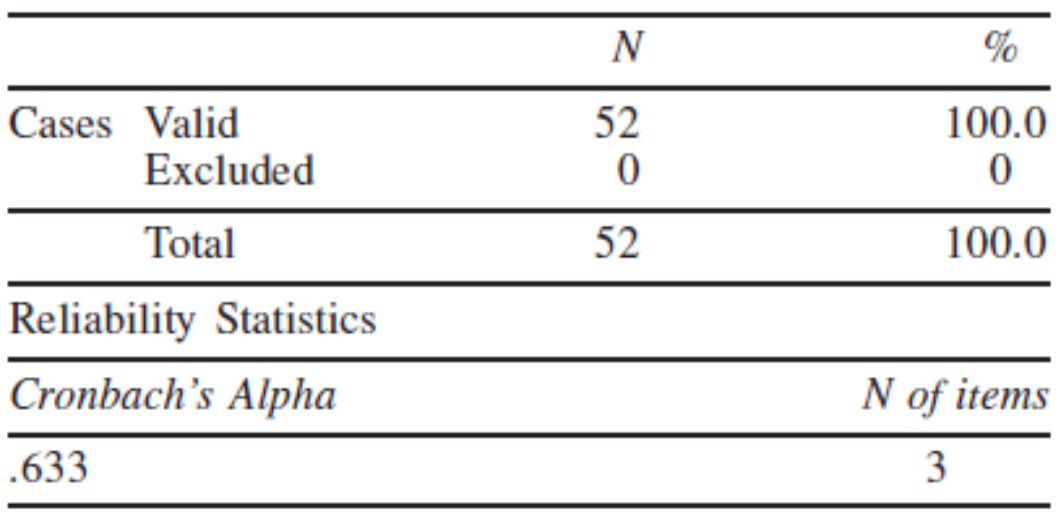

Quantitative data analysis allows validating the Integrated Model of Communication for Social Change with particular regard to the measuring of collective self-efficacy as an outcome of the process of social change. The process is generally initiated by a catalyst, which in this case, is represented by SMD. After getting exposed to development communication initiatives, members of the community are engaged in a discussion which allows them to recognize problems, express individual and group interests and lastly draft an action plan which lead to collective action. Furthermore, data analysis revealed how development communication interventions, in the form of documentary screenings and post-screening discussions, can contribute to the increase of the level of collective selfefficacy amongst the researched sample group. These data provides encouraging findings for the present study.

The qualitative analysis strongly support the results mentioned above. Thematic patterns were isolated to facilitate content analysis. From the discussion with the interviewees, it appears that documentary screenings and discussions with the audience are able to provoke a reaction that can lead to some form of "action" or changes of status. These interventions are based on a theoretical framework that places a strong emphasis on the dialogical and participated process between the audience and the facilitator. Moreover parasocial interactions allow the audience to relate to documentary characters and follow their behaviour patterns. This is the case of interviewees who declared to have openly disclosed their HIV/AIDS status to their family or community because inspired by characters' actions.

Findings reveal that post-screening discussions could help audiences to become more aware of the issues affecting their community and in identifying new needs. This process of social learning is initiated by a "dialogical communication" as described by Freire (1972). The facilitator, or the person who leads the discussion, has the responsibility to assist the audience in identifying needs and designing a "plan of action" or a "way forward". Post screening discussions have the power to bring people together and to make them more united and keen to co-operate to achieve common goals. The thematic analysis of semi-structured interviews and focus group discussions showed that development communication activities run in prisons by SMD have the capacity to stimulate collective action and to unite people. Some of the inmates interviewed reported that post- 
screening discussions highly contributed to the formation of support groups within the prison system. Finally the results show that development communication in the form of facilitated post-screening discussion can increase the level of self-efficacy of a group as well as the level of trust or confidence amongst the members.

Table 4: A $t$-test run with the last set of three questions

One-Sample Statistics

\begin{tabular}{|c|c|c|c|c|c|}
\hline & $N$ & & Mean & Std. deviation & Std. error mean \\
\hline meanSCREEN2 & 52 & & 2.9551 & .19835 & .02751 \\
\hline \multicolumn{6}{|l|}{ One Sample Test } \\
\hline & \multicolumn{5}{|c|}{ Test Values $=0$} \\
\hline & $t$ & $d f$ & $\begin{array}{c}\text { Sig. } \\
\text { (2-tailed) }\end{array}$ & $\begin{array}{c}\text { Mean } \\
\text { difference }\end{array}$ & $\begin{array}{c}95 \% \\
\text { Confidence... } \\
\text { Lower } \\
\end{array}$ \\
\hline meanSCREEN2 & 107.437 & 51 & .000 & 2.95513 & 2.8999 \\
\hline
\end{tabular}

This generates the idea that "together" people can achieve better results and advocate for their needs. In this regard, it can be argued that SMD have played a vital role in using development communication programmes to inform and educate people and encourage them to take action. Films are also used as a powerful tool that enables different audiences to reflect on their challenges, identify problems and finally design a plan of action. This is, in essence, the meaning of the "learning cycle", underlining the methodology of SMD, which is divided in the following steps: a) watching the film; b) reflecting on the film; c) looking at the bigger picture; and d) taking action.

\section{Conclusion}

The concept of development communication has evolved throughout the years, moving from a top-down linear process aimed at shifting individuals' attitudes and behaviours to a bottom-up and participatory process, seeking consensus and ownership at grassroots level. For this reason, the role of communication applied to the field of development cannot be limited to the mere transfer of knowledge from a sender to a receiver, but it has to be conceived as a two-way practice. Communication should be able to lead audiences of poor and disadvantaged people to critically understand the causes of their problems and identify solutions to be achieved with a collective effort. Therefore, passive and linear forms of communication are outdated and ineffective and need to be replaced by more integrated forms of communication, forms that are able to "conscientise" and educate communities on problem solving.

This research was aimed at assessing how development communication programmes run by SMD in Lesotho could foster collective forms of action and lead to resource mobilisation. Both quantitative and qualitative findings revealed that documentary and post-screenings discussions contribute to increase the level of confidence or efficacy of the target groups. This can be either observed in the individual's belief in the power to produce change -self-efficacy- or in a group's shared belief in collective action -collective self-efficacy. In particular, quantitative findings confirmed that documentary screenings and training programmes run by SMD strongly contribute to increase the level of collective self-efficacy amongst community members in the researched area. To summarise, the continuous exposure to development communication programmes run by SMD positively influenced the level of collective self-efficacy of HIV/Aids support 
group members with regard to their groups or communities. Lastly, the results of the research revealed that the dialogical process between a facilitator and his/her audience helped individuals to identify problems and needs and to plan collective forms of action.

For the purposes of this study, the Integrated Model of Communication for Social Change has provided a useful framework of analysis to explain how the "learning cycle" and the methodology used by SMD could stimulate collective forms of action. Empirically, determined findings helped to illustrate how the Integrated Model of Communication for Social Change functions and how this model of analysis applies to a case study. This research has demonstrated that development communication programmes based on community dialogue and participation can foster collective action and ultimately lead to social change.

\section{Recommendations}

SMD has been operating for over 10 years to create a safe environment for open and meaningful conversation, to reduce stigma and to equip people with the ability to make informed decisions. Previous evaluation reports assessed the role of SMD and the impact of their interventions on behaviour change at individual level. This study contributed to highlight the effect of the "learning cycle" on collective action. Therefore, some recommendations are provided to SMD to implement their activities more effectively. These include first, concerning the prison programme, findings revealed that Leribe prison is the site where documentary screenings and training programme produced the best results. Those inmates who were initially trained by SMD in 2009 later decided to train other inmates who currently facilitate documentary screenings in prison. In future, it will be relevant to continue focusing on this correctional institution, where positive relationships were established with the staff and the inmates, rather than to stretch the organisation's capacity and waste resources to reach other correctional institutions that might also not have the necessary screening equipment. Secondly, using ex-inmates to facilitate screening discussions in different communities of Lesotho has a positive effect on the social rehabilitation of individuals previously detained. These people, who in some cases are HIV positive, are often facing discrimination from community members and therefore to act as facilitators can help them to be reintegrated into their communities and to receive an income. Thirdly, screening and post-screening discussions have the power to unite people and stimulate collective action. Therefore, the organisation should expand lobbying and advocacy activities by providing support to those individuals/organisations that manifest their intention to mobilise resources around a specific issue. Finally, SMD should provide more capacity building activities to be included in their training sessions. This will help trained facilitators to support groups' initiatives and collective action. 


\section{References}

Bandura A 1986. Social Foundations of Thought and Action: A Social Cognitive Theory. Englewood Cliffs, New Jersey: Prentice Hall.

Brown WJ, Singhal A 1996. The entertainment-education communication strategies: Past struggles, present status, future agenda. Jurnal Komunikasi, 12: 19-36.

Brown WJ, Singhal A 1999. Entertainment-education media strategies for social change: Promises and problems. In: DP Demers, K Viswanath (Eds.): Mass Media, Social Control and Social Change. Ames, IA: Iowa State University Press.

Figueroa ME, Kincaid DL, Rani $M$, Lewis G 2002. Communication for social change: An integrated model for measuring the process and its outcomes. The Communication for Social Change Working Paper Series, 1: 1-38. New York, NY: Rockefeller Foundation/CFSC Consortium.

Freire P 1972. Pedagogy of the Oppressed. New York, NY: Harder and Harder.

Kincaid DL 2000. Social networks, ideation, and contraceptive behavior in Bangladesh: A longitudinal analysis. Social Science and Medicine, 50: 215-31.

Kincaid DL 2002. Drama, emotion and cultural convergence. Communication Theory, 12(2): 136-152.

McCall E 2011. Communication for Development: Strengthening the Effectiveness of the United Nations. UNDP. From <http: //www.unicef.org/cbsc/ files/Inter agency_C4D_Book_2011.pdf> (Retrieved on July 10, 2013).

Obregon R, Waisbord S (Eds.) 2012. The Handbook of Global Health Communication. Hoboken, NJ: John Wiley and Sons.

Papa MJ, Singhal A, Law S, Pant S, Sood S, Rogers EM, Shefner-Rogers CL 2000. Entertainment education and social change: An analysis of parasocial interactions, social learning, collective efficacy and para- doxical communication. Journal of Communication, 50(4): 31-35.

Rasak O, Adesina $\mathrm{T}$ 2011. The impact of radio entertainment-education program on sexual practices of selected farm families in Ebonyi State. Ozean Journal of Social Science, 4(1): 23-35.

Rogers E 1976. Communication and development: The passing of the dominant paradigm. In: E Rogers (Eds.): Communication and Development: Critical Perspectives. Beverly Hills, CA: Sage.

Rogers EM, Kincaid DL1981. Communication Networks: Toward a New Paradigm for Research. New York, NY: The Free Press.

Rogers EM, Singhal A 2002. A theoretical agenda for entertainment education. Communication Theory, 12(2): 117-135.

Shefner-Rogers CL, Rogers EM, Singhal A 1998. Parasocial interaction with the television soap operas "Simplemente Maria" and "Oshin". Keio Communi- cation Review, 20: 3-18.

Singhal A, Rogers EM, Brown WJ 1993. Harnessing the potential of educationentertainment telenovelelas. Gazette, 51: 1-18.

Singhal A, Sood S, Rogers EM, Law S, Vaughan PW 1998. Effects of "Tinka-Tinka Sukh": A Radio Soap Opera in India on Gender Equality. Women Rights and Family Planning. International Conference on Popu- lation Development.

Tufte T 2001. Entertainment-education and participation: Assessing the communication strategy of "Soul City". Journal of International Communication, 7(2): 25-51.

\section{https://repository.uwc.ac.za/}


Tufte $\mathrm{T}$ 2002. Edutainment in HIV/AIDS prevention. Building on the Soul City experience in South Africa. In: J Servaes (Eds.): Approaches to Development Communication. Chapter 13. Paris, France: UNESCO, pp. 394-419. 